\title{
Anti-platelet activity of mineral-balanced deep sea water is mediated via the regulation of Akt and ERK pathway crosstalk
}

\author{
GI SUK NAM, KYU-SHIK LEE and KYUNG-SOO NAM \\ Department of Pharmacology and Intractable Disease Research Center, School of Medicine, \\ Dongguk University, Gyeongju, Gyeongsangbuk-do 38066, Republic of Korea
}

Received July 9, 2019; Accepted November 14, 2019

DOI: 10.3892/ijmm.2019.4424

\begin{abstract}
Mineral-balanced deep sea water (MBDSW), an unlimited natural sea source, has been demonstrated to minimize the risk of developing cardiovascular diseases, such as obesity, hypertension, inflammation and hyperlipidemia. This study investigated the effects of MBDSW [magnesium $(\mathrm{Mg})$ :calcium $(\mathrm{Ca})$ ratio, 3:1] on platelet activation. MBDSW significantly inhibited the collagen- and thrombin-induced platelet aggregation of human platelets. In collagen-induced platelets, MBDSW inhibited intracellular calcium mobilization, granule secretion [serotonin, adenosine triphosphate (ATP) and P-selectin expression] and thromboxane $\mathrm{A}_{2}$ $\left(\mathrm{TXA}_{2}\right)$ production. Moreover, MBDSW markedly inhibited Akt and extracellular signal-regulated kinase (ERK) phosphorylation, but not that of c-Jun N-terminal kinase (JNK) and p38. Moreover, MBDSW phosphorylated inositol 1,4,5-triphosphate receptor $\left(\mathrm{IP}_{3} \mathrm{R}\right)$ and vasodilator-stimulated phosphoprotein (VASP), and it increased the cyclic adenosine monophosphate (cAMP) level in collagen-induced human platelets. Dipyridamole, a phosphodiesterase (PDE) inhibitor, significantly increased the cAMP level and regulated the Akt, ERK and VASP $\left(\mathrm{Ser}^{157}\right)$ levels in a manner similar to that of MBDSW. In addition, LY294002, an Akt inhibitor, inhibited the phosphorylation of ERK, and U0126, an ERK inhibitor, inhibited the phosphorylation of Akt. Taken together, the results of the present investigation suggest that the inhibitory effects of MBDSW on platelet aggregation may be associated with the cross-inhibition of Akt and ERK phosphorylation. These results strongly indicate that MBDSW may have preventive or therapeutic potential for platelet aggregation-mediated diseases, such as thrombosis, atherosclerosis and myocardial infarction.
\end{abstract}

Correspondence to: Professor Kyung-Soo Nam, Department of Pharmacology and Intractable Disease Research Center, School of Medicine, Dongguk University, 123 Dongdae-ro, Gyeongju, Gyeongsangbuk-do 38066, Republic of Korea

E-mail:namks@dongguk.ac.kr

Key words: mineral-balanced deep sea water, platelet aggregation, cardiovascular disease, thrombosis

\section{Introduction}

Platelets are non-nucleated cells that are produced in the cytoplasm of intramedullary megakaryocytes (1). These platelets circulate throughout the bloodstream, performing hemostasis and preventing bleeding in conjunction with coagulation factors. However, these platelet functions produce blood clots that potentially block arterial, microvascular and capillary blood flows, causing cardiovascular diseases (CVDs), including angina pectoris, myocardial infarction and atherosclerosis (2).

Collagen is a protein abundantly present in the extracellular matrix of the blood vessel wall, providing flexibility to withstand the outward forces exerted by arterial pressure (3). Under normal blood flow situations, collagen is not exposed to the lumen. However, when the collagen leaks into the lumen, due to damage or sclerosis of the blood vessel walls by CVD risk factors, glycoprotein (GP)-VI and GP-IX-V complex receptors on the surface of platelets bind to the collagen (4). Fc receptor- $\gamma$ chain and Src family kinase associated with GP-VI lead to the phosphorylation and activation of phospholipase $\mathrm{C}_{\gamma_{2}}$, catalyzing the hydrolysis of phosphatidylinositol 4,5-bisphosphate to diacylglycerol and inositol trisphosphate $\left(\mathrm{IP}_{3}\right)$. In such instances, agonist-binding receptors induce granule release, integrin activation, thromboxane $\mathrm{A}_{2}\left(\mathrm{TXA}_{2}\right)$ production, and as a consequence, platelet aggregation $(5,6)$.

Deep sea water (DSW) is an abundant sea resource located at depths as deep as $200 \mathrm{~m}$ below sea level. It contains high concentrations of minerals, such as magnesium $(\mathrm{Mg})$, calcium $(\mathrm{Ca})$, potassium $(\mathrm{K})$ and sodium $(\mathrm{Na})$, as well as several trace minerals. Currently, DSW is being developed in Korea, Japan and Taiwan for use in various applications in the aquaculture, agriculture and food industries $(7,8)$. Although various industries are trying to adopt and use DSW, such as the food industry (e.g., mineral water, deep sea water salt, confectioneries, etc.), there is a lack of evidence that DSW has biologically beneficial functions. The biological effects of DSW on obesity, hypertension, inflammation, atopic eczema/dermatitis syndrome and cancer have been reported in several studies (7,9-12). Moreover, DSW has been shown to exert suppressive effects on hyperlipidemia and atherosclerosis in animals fed a high cholesterol diet (13-15). Previously, it was demonstrated that DSW inhibited doxorubicin-induced epithelial-mesenchymal transition by inhibiting the extracellular signal-activated protein kinase (ERK1/2), p38 and PI3K/Akt signaling 
pathways (15). Mitogen-activated protein kinases (MAPKs), such as the ERK, c-Jun N-terminal kinase (JNK) and p38, and Akt signaling pathways, play primary roles in the amplification of platelet aggregation, granule secretion and integrin $\alpha_{\mathrm{IIb}} \beta_{3}$ activation induced by agonists (16-18). However, to the best of our knowledge, there is no study available to date describing a role of DSW in the inhibition of platelet activation, which is another cause of CVDs, including angina pectoris, myocardial infarction and atherosclerosis.

In this study, since the original DSW is high in $\mathrm{Na}$ and requires hardness control, experiments were performed using a mineral-balanced DSW (MBDSW). The anti-platelet activity of MBDSW was investigated using collagen- and thrombin-induced platelet aggregation. Furthermore, whether MBDSW inhibits granule secretion, platelet-activating molecules, integrin and the MAPK and Akt signaling pathways was also evaluated.

\section{Materials and methods}

Materials and reagents. Collagen and thrombin were purchased from the Chrono-Log Co. The thromboxane $\mathrm{B}_{2}\left(\mathrm{TXB}_{2}\right)$ ELISA kit, Cyclic AMP ELISA kit and dipyridamole were purchased from Cayman Chemical Co. The CytoTox $96{ }^{\circledR}$ Non-Radioactive Cytotoxicity assay (cat. no. G1780) was purchased from Promega. The serotonin ELISA kit was purchased from Labor Diagnostika Nord GmbH \& Corp. Fura-2/acetoxymethyl ester (AM) and Alexa Fluor 488-conjugated fibrinogen were purchased from Molecular Probes. APC anti-human CD62P (P-selectin, cat. no. 304910) antibody was purchased from BioLegend Inc. The adenosine triphosphate (ATP) assay kit was purchased from Biomedical Research Service Center. Protease inhibitor cocktail and phosphatase inhibitor cocktail were purchased from GenDEPOT, and antibodies against ERK1/2 (cat. no. 4695), phospho-ERK1/2 ( $\mathrm{Thr}^{202} / \mathrm{Tyr}^{204}$; cat. no. 4370), p38 (cat. no. 8690), phospho-p38 (cat. no. 4511), JNK (cat. no. 9258), phospho-JNK (cat. no. 4668), Akt (cat. no. 4691), phospho-Akt ( $\operatorname{Ser}^{473}$; cat. no. 9271), phospho-Akt ( $\mathrm{Thr}^{308}$; cat. no. 2965), vasodilator-stimulated phosphoprotein (VASP; cat. no. 3112), phospho-VASP (Ser ${ }^{157}$; cat. no. 3111), phospho-inositol 1,4,5-triphosphate receptor $\left(\mathrm{IP}_{3} \mathrm{R}\right.$; cat. no. 8548) and glyceraldehyde 3-phosphate dehydrogenase (GAPDH; cat. no. 5174) were purchased from Cell Signaling Technology. $\beta$-actin antibody (cat.no. sc-69879) was purchased from Santa Cruz Biotechnology. LY294002 and U0126 were purchased from LC laboratories. HRP-conjugated goat anti-rabbit IgG (cat. no. 31460) and bi-cinchoninic acid (BCA) protein assay kits were purchased from Pierce Biotechnology. Polyvinylidene fluoride (PVDF) membrane was purchased from PallLife Sciences.

Preparation of MBDSW. MBDSW was obtained from the Seawater Utilization Plant Research Center in the Research Institute of Ships and Ocean Engineering. DSW was pumped from a depth of $500 \mathrm{~m}$ in the East Sea of Korea. To remove salts and minerals, it underwent reverse osmosis filtration and electrodialysis, as previously described (14). Refined minerals were then added to the treated MBDSW to generate a hardness of $3,428(\mathrm{H} 3,428)$ containing $711.72 \mathrm{mg} / 1 \mathrm{Mg}$, $203.84 \mathrm{mg} / \mathrm{l} \mathrm{Ca}, 39.65 \mathrm{mg} / \mathrm{l} \mathrm{Na}$ and $17.31 \mathrm{mg} / \mathrm{l} \mathrm{K}$ (Table I).
After manufacturing the MBDSW (Mg:Ca ratio, 3:1), there is a slight difference in the analysis ( $\mathrm{Mg}: \mathrm{Ca}$ ratio, 3.49:1). MBDSW $(\mathrm{H} 3,428)$ was then diluted with filtered MBDSW (H0) to prepare MBDSW of various hardness levels. The hardness $(\mathrm{H})$ was calculated using the following formula: Hardness $=[\mathrm{Mg}(\mathrm{mg} / \mathrm{l}) \times 4.1]+[\mathrm{Ca}(\mathrm{mg} / \mathrm{l}) \times 2.5]$, as previously described (14).

Preparation of washed human platelets and measurement of platelet aggregation. Once the platelet plug has been formed by the activated platelets, the coagulation factors presented in plasma are activated in a sequence of events known as the 'coagulation cascade', which leads to the formation of fibrin from fibrinogen plasma protein (19). Therefore, this study evaded all response to any secondary hemostasis effects using the washed platelet aggregation method. This study used blood samples obtained from healthy volunteers (17 to 59 years of age). This study was approved by the Dongguk University Gyeongju Institutional Review Board (DUG IRB 20180014-04). Volunteer written consent was waivered in this study. A total of 13 human platelet-rich plasma (PRP) with an acid-citrate-dextrose solution ( $0.8 \%$ citric acid, $2.2 \%$ sodium citrate and $2.45 \%$ glucose) was collected and obtained from the Korean Red Cross Blood Center (Daegu, Korea) from July, 2018 to December, 2018. Human PRP was centrifuged for $10 \mathrm{~min}$ at $125 \mathrm{xg}$ at $25^{\circ} \mathrm{C}$ to remove other cells and then centrifuged for $10 \mathrm{~min}$ at $1,300 \mathrm{xg}$ at $25^{\circ} \mathrm{C}$ to obtain platelet pellets. The platelet pellets were washed twice with washing buffer (138 mM NaCl, $2.7 \mathrm{mM} \mathrm{KCl}, 12 \mathrm{mM} \mathrm{NaHCO}, 0.36 \mathrm{mM}$ $\mathrm{NaH}_{2} \mathrm{PO}_{4}, 5.5 \mathrm{mM}$ glucose and $1 \mathrm{mM} \mathrm{Na} \mathrm{NDTA}_{2} \mathrm{pH}$ 6.5) and then resuspended in a suspension buffer $(138 \mathrm{mM} \mathrm{NaCl}$, $2.7 \mathrm{mM} \mathrm{KCl}, 12 \mathrm{mM} \mathrm{NaHCO}, 0.36 \mathrm{mM} \mathrm{NaH}_{2} \mathrm{PO}_{4}, 0.49 \mathrm{mM}$ $\mathrm{MgCl}_{2}, 5.5 \mathrm{mM}$ glucose and $0.25 \%$ gelatin, $\mathrm{pH}$ 6.9) to a final concentration of $1 \times 10^{8}$ cells $/ \mathrm{ml}$, as previously described (20). All of the above-mentioned procedures were performed at $25^{\circ} \mathrm{C}$ to avoid any effects (i.e., platelet activation) related to temperature.

Platelet aggregation was measured using an aggregometer (Chrono-Log, Corp.) at a constant stirring speed of $50 \mathrm{x} \mathrm{g.} \mathrm{In}$ the experiment, platelets were pre-incubated with MBDSW at $37^{\circ} \mathrm{C}$ in the presence of $2 \mathrm{mM} \mathrm{CaCl}{ }_{2}$ prior to the addition of collagen $(3 \mu \mathrm{g} / \mathrm{ml})$ or thrombin $(0.05 \mathrm{U} / \mathrm{ml})$. Each aggregation rate $(\%)$ was recorded for $5 \mathrm{~min}$.

Measurement of lactate dehydrogenase. Platelet cytotoxicity was determined by the leakage of lactate dehydrogenase (LDH) from the cytosol. Washed human platelets $\left(10^{8}\right.$ cells $\left./ \mathrm{ml}\right)$ were incubated with various concentrations of MBDSW (H250 to $\mathrm{H} 2,000$ ) for $30 \mathrm{~min}$ at $37^{\circ} \mathrm{C}$, and then centrifuged with $2,000 \mathrm{x} \mathrm{g}$ for $5 \mathrm{~min}$ at room temperature. The supernatant $(50 \mu \mathrm{l})$ incubated with cytotoxicity assay reagent mix $(50 \mu \mathrm{l})$ for $30 \mathrm{~min}$ at room temperature was measured using a SpectraMax M2e (Molecular Devices). A maximal value of cytotoxicity was recorded in $0.05 \%$ triton $\mathrm{X}-100$. Percentage cytotoxicity was calculated as follows: Cytotoxicity $(\%)=100 \mathrm{x}$ (sample LDH release/maximum LDH release).

Measurement of cytosolic calcium ion concentration. Human PRP was incubated with Fura-2/AM $(5 \mu \mathrm{M})$ at $37^{\circ} \mathrm{C}$ for $1 \mathrm{~h}$ in the dark. Washed, Fura-2/AM-loaded human platelets 
Table I. Mineral content of original DSW and MBDSW used in this study.

\begin{tabular}{lcc}
\hline Major elements & MBDSW $(\mathrm{mg} / \mathrm{l})$ & Original DSW (mg/l) \\
\hline $\mathrm{Mg}$ & 711.72 & 1,269 \\
$\mathrm{Ca}$ & 203.84 & 421 \\
$\mathrm{~K}$ & 17.31 & 396 \\
$\mathrm{Na}$ & 39.65 & 10,567 \\
$\mathrm{~Pb}$ & $\mathrm{ND}$ & $<0.005$ \\
$\mathrm{Hg}$ & $\mathrm{ND}$ & $\mathrm{ND}$ \\
$\mathrm{Cd}$ & $\mathrm{ND}$ & $<0.001$ \\
$\mathrm{Sr}$ & 3.55 & 1.68 \\
\hline
\end{tabular}

MBDSW, mineral-balanced deep sea water; DSW, deep sea water; $\mathrm{Mg}$, magnesium; $\mathrm{Ca}$, calcium; $\mathrm{K}$, potassium; $\mathrm{Na}$, sodium; $\mathrm{Pb}$, lead; $\mathrm{Hg}$, mercury; Cd, cadmium; $\mathrm{Sr}$, strontium; ND, not detected.

were prepared using the procedure described above, and $1 \times 10^{8}$ platelets $/ \mathrm{ml}$ were pre-treated with MBDSW for $2 \mathrm{~min}$ at $37^{\circ} \mathrm{C}$ and then stimulated with collagen $(3 \mu \mathrm{g} / \mathrm{ml})$ for $5 \mathrm{~min}$. Fluorescence was recorded with a spectrofluorometer (SFM 25; Bio-Teck Instruments) with an excitation wavelength that changed every $0.5 \mathrm{sec}$ from 340 to $380 \mathrm{~nm}$; the emission wavelength was set at $510 \mathrm{~nm}$. The calcium ion concentration $\left(\left[\mathrm{Ca}^{2+}\right]_{\mathrm{i}}\right)$ was calculated using the method developed by Schaeffer and Blaustein (21). The following formula was used: $\left[\mathrm{Ca}^{2+}\right]_{\mathrm{i}}=224 \mathrm{nM} \times\left(F-F_{\min }\right) /\left(F_{\max }-F\right)$, where $224 \mathrm{nM}$ is the dissociation constant of Fura-2-Ca ${ }^{2+}$ complex, and $F_{\min }$ and $F_{\max }$ are fluorescence intensities at low and high $\mathrm{Ca}^{2+}$ concentrations, respectively.

Measurement of serotonin release. Platelet aggregation was terminated after $5 \mathrm{~min}$ of stimulation by the addition of $5 \mathrm{mM}$ ice-cold EDTA followed by centrifuging the samples $\left(5,000 \mathrm{x} \mathrm{g}, 3 \mathrm{~min}\right.$, at $\left.4^{\circ} \mathrm{C}\right)$. The supernatant was used to determine the level of serotonin release. Samples were reacted with acylation buffer for $15 \mathrm{~min}$ at room temperature. Acylated samples were incubated with serotonin antiserum in the serotonin microtiter strips for $15 \mathrm{~min}$ at room temperature. The level of serotonin release was measured using a SpectraMax M2e (Molecular Devices) microplate reader.

Measurement of ATP release. Platelet aggregation was stopped after $5 \mathrm{~min}$ of stimulation, by adding $5 \mathrm{mM}$ ice-cold EDTA followed by centrifuging the samples $(5,000 \mathrm{xg}, 3 \mathrm{~min}$, at $4^{\circ} \mathrm{C}$ ). The supernatant was used to determine the level of ATP release. Samples were reacted with ATP assay solution. The level of ATP release was measured using a SpectraMax M2e (Molecular Devices) microplate reader.

Measurement of $P$-selectin expression and fibrinogen binding to integrin $\alpha_{I I b} \beta_{3}$. Platelets, pre-incubated with MBDSW (H250 to $\mathrm{H} 2,000)$, were stimulated with collagen $(3 \mu \mathrm{g} / \mathrm{ml})$ at $37^{\circ} \mathrm{C}$ in the presence of $2 \mathrm{mM} \mathrm{CaCl}_{2}$. The platelets were centrifuged $\left(1,500 \mathrm{x} \mathrm{g}, 3 \mathrm{~min}\right.$, at $\left.4^{\circ} \mathrm{C}\right)$ consecutively followed by fixation using $0.5 \%$ paraformaldehyde. The fixed platelets were then washed 3 times via centrifugation at $2,000 \mathrm{xg}$ for $5 \mathrm{~min}$, at $4^{\circ} \mathrm{C}$ and resuspended in cool phosphate-buffered saline (PBS) containing $5 \%$ bovine serum albumin (BSA) and $1 \%$ sodium azide. Platelets were incubated with FITC-conjugated CD62P antibody $(4 \mu \mathrm{g} / \mathrm{ml})$ and Alexa Fluor 488 -conjugated human fibrinogen $(200 \mu \mathrm{g} / \mathrm{ml})$ in $3 \%$ bovine serum albumin/PBS for $30 \mathrm{~min}$ at $4^{\circ} \mathrm{C}$ in the dark. Subsequently, flow cytometric analysis was performed on a FACSCalibur II flow cytometer using CellQuest software.

Measurement of cyclic AMP level. Platelets, pre-incubated with MBDSW (H250 to H2,000) or dipyridamole $(40 \mu \mathrm{M})$ for $2 \mathrm{~min}$ at $37^{\circ} \mathrm{C}$, were stimulated with collagen $(3 \mu \mathrm{g} / \mathrm{ml})$ for $5 \mathrm{~min}$ at $37^{\circ} \mathrm{C}$ in the presence of $2 \mathrm{mM} \mathrm{CaCl}_{2}$. A sample was then added $80 \%$ ice-cold ethanol and underwent vortexing for pre-treatment. The sample was left at room temperature for $5 \mathrm{~min}$ and centrifuged at $2,000 \mathrm{x}$ g for $10 \mathrm{~min}$ at $4^{\circ} \mathrm{C}$. Samples were reacted with cAMP antiserum and cAMP tracer in a mouse anti-rabbit IgG-coated plate overnight at $4^{\circ} \mathrm{C}$. The level of cAMP in the supernatant was determined using a SpectraMax M2e (Molecular Devices) microplate reader.

Measurement of $\mathrm{TXA}_{2}$ production. Platelets, pre-incubated with MBDSW, were stimulated with collagen $(3 \mu \mathrm{g} / \mathrm{ml})$ at $37^{\circ} \mathrm{C}$ in the presence of $2 \mathrm{mM} \mathrm{CaCl}_{2}$. Platelet aggregation was terminated after $5 \mathrm{~min}$ of stimulation by the addition of $5 \mathrm{mM}$ ice-cold EDTA including $0.2 \mathrm{mM}$ indomethacin followed by centrifuging the samples $(5,000 \mathrm{x} \mathrm{g}, 3 \mathrm{~min}$, at $4^{\circ} \mathrm{C}$ ). Supernatants were diluted 1:500 and used in assays. Samples were reacted with $\mathrm{TXB}_{2}$ antiserum and $\mathrm{TXB}_{2}$ tracer in a mouse anti-rabbit IgG-coated plate overnight at $4^{\circ} \mathrm{C}$. The level of $\mathrm{TXB}_{2}$ in the supernatant was determined using a SpectraMax M2e (Molecular Devices) microplate reader.

Western blot analysis. Platelets, pre-incubated with MBDSW (H250 to H2,000), dipyridamole ( $40 \mu \mathrm{M}), \mathrm{LY} 294002$ (2 and $20 \mu \mathrm{M})$ or $\mathrm{U} 0126(2$ and $20 \mu \mathrm{M})$ for $2 \mathrm{~min}$ at $37^{\circ} \mathrm{C}$, were stimulated with collagen $(3 \mu \mathrm{g} / \mathrm{ml})$ for $5 \mathrm{~min}$ at $37^{\circ} \mathrm{C}$ in the presence of $2 \mathrm{mM} \mathrm{CaCl}_{2}$. Platelet aggregation was terminated after $5 \mathrm{~min}$ of stimulation by the addition of protease and phosphatase inhibitor-containing RIPA lysis buffer $(50 \mathrm{mM}$ pH 7.5 Tris- $\mathrm{HCl}, 150 \mathrm{mM} \mathrm{NaCl}, 1 \%$ Triton X-100, $1 \%$ sodium deoxycholate, $0.1 \%$ SDS and $2 \mathrm{mM}$ EDTA). The protein concentration was determined by BCA assay; an equal amount of protein in platelet lysates was separated via 8 to $12 \%$ SDS-polyacrylamide gel electrophoresis and then transferred onto a PVDF membrane. The PVDF membrane was blocked with $1 \%$ BSA in TBS buffer. The primary antibody $(1: 3,000)$ was reacted overnight at $4^{\circ} \mathrm{C}$, after which, a secondary antibody $(1: 5,000)$ reaction was performed for $2 \mathrm{~h}$ at room temperature. The protein bands were visualized with a chemiluminescence substrate and photographed using a LAS-4000 (Fujifilm) luminescent image analyzer. Densitometric analysis was performed using image $\mathbf{J}$ version 1.6.0_20 (National Institutes of Health) with data from at least 3 independent experiments.

Statistical analysis. The experimental results are presented as the means \pm standard deviation (SD) values accompanied by the number of observations. Statistical significance was determined by analyzing variance. Significant differences among groups in experiments were assessed by undertaking analysis 
of variance (ANOVA). When the ANOVA results indicated significant differences among group means, the groups were compared by the Newman-Keuls method. A value of $\mathrm{P}<0.05$ was considered to indicate a statistically significant difference.

\section{Results}

Effects of MBDSW on collagen- and thrombin-induced human platelet aggregation, and cytotoxicity. Platelet aggregation was determined using a light transmission aggregometer. The concentration of collagen used was $3 \mu \mathrm{g} / \mathrm{ml}$, which was the threshold concentration required to induce maximal aggregation (Fig. S1). As the threshold concentration of thrombin $(0.2 \mathrm{U} / \mathrm{ml})$ is a very high concentration, the concentration of thrombin used was $0.05 \mathrm{U} / \mathrm{ml}$. The effects of various hardness levels of MBDSW on platelet aggregation induced by collagen and thrombin were examined and it was observed that MBDSW inhibited platelet aggregation induced by collagen $(3 \mu \mathrm{g} / \mathrm{ml})$ and thrombin $(0.05 \mathrm{U} / \mathrm{ml})$ in a hardness-dependent manner (Fig. 1A and B). Subsequently, it was confirmed that the presence of calcium in MBDSW did not automatically affect platelet aggregation (Fig. 1C). Furthermore, Ca plus Mg, equivalent to MBDSW (H250 and H1,000), inhibited platelet aggregation induced by collagen $(3 \mu \mathrm{g} / \mathrm{ml})$ (Fig. S2). In addition, LDH assay revealed that MBDSW (H250 to $\mathrm{H} 2,000)$ incubated with the platelets for $30 \mathrm{~min}$ did not increase LDH leakage in the platelets (Fig. 1D). These results suggested that MBDSW inhibited platelet aggregation without affecting cytotoxicity.

MBDSW reduces collagen-induced $\left[\mathrm{Ca}^{2+}\right]_{i}$ mobilization and increases $I P_{3} R$ phosphorylation. Intracellular calcium $\left(\left[\mathrm{Ca}^{2+}\right]_{\mathrm{i}}\right)$ is considered an important molecule for platelet activation, such as the inside-out signaling activation of integrin $\alpha_{\mathrm{IIb}} \beta_{3}$ and thrombus formation (22). Thus, the inhibitory effects of MBDSW on the collagen-induced increase in $\left[\mathrm{Ca}^{2+}\right]_{i}$ levels were investigated. Pre-treatment of the platelets with various hardness levels of MBDSW significantly prevented the collagen-induced increase in $\left[\mathrm{Ca}^{2+}\right]_{\mathrm{i}}$ levels (Fig. 2A). To reveal the inhibitory mechanisms of MBDSW associated with $\left[\mathrm{Ca}^{2+}\right]_{i}$ mobilization, the association between $\mathrm{IP}_{3} \mathrm{R}$ and $\left[\mathrm{Ca}^{2+}\right]_{i}$ mobilization was evaluated. As shown in Fig. 2B, MBDSW increased $\mathrm{IP}_{3} \mathrm{R}$ phosphorylation in a hardness-dependent manner.

$M B D S W$ reduces granule secretion. When platelets are activated via agonist stimulation, platelets release granules. Therefore, it was investigated whether MBDSW affects $\alpha$-granule and dense granule secretion in collagen-induced platelet aggregation. Collagen $(3 \mu \mathrm{g} / \mathrm{ml})$ alone markedly increased ATP and serotonin secretion from dense granules. However, the ATP and serotonin secretions were significantly decreased by MBDSW in a hardness-dependent manner (Fig. 3A and B). To determine whether MBDSW inhibits $\alpha$-granule secretion, $\mathrm{P}$-selectin expression was examined by flow cytometry. The results revealed that MBDSW significantly inhibited P-selectin expression in a hardness-dependent manner (Fig. 3C and D).

MBDSW inhibits activation of integrin $\alpha_{I I b} \beta_{3}$. Integrin $\alpha_{\mathrm{II}} \beta_{3}$ undergoes a conformational transition upon platelet activation and binds to fibrinogen (23). To determine whether
MBDSW inhibits the activation of integrin $\alpha_{\mathrm{II}} \beta_{3}$, the binding of fibrinogen to the activated integrin $\alpha_{\mathrm{II}} \beta_{3}$ was examined by flow cytometry. The binding of fibrinogen to the activated integrin $\alpha_{\mathrm{II}} \beta_{3}$ was significantly inhibited in MBDSW-treated platelets (Fig. 4A and B). Furthermore, we examined the effect of MBDSW on VASP phosphorylation as a regulator of integrin $\alpha_{\mathrm{II}} \beta_{3}$ activation (24). In collagen-activated platelets, VASP $\left(\operatorname{ser}^{157}\right)$ was shown to be directly phosphorylated (Fig. 4C), an action that involves a collagen-related feedback inhibitory signaling pathway (25). However, MBDSW markedly increased the phosphorylation of VASP $\left(\operatorname{Ser}^{157}\right)$ to a level greater than that observed with collagen only (Fig. 4C).

$M B D S W$ alters the $c A M P$ level. Since it has been well established that cAMP inhibits the activation of platelets and stimulates VASP phosphorylation in activated platelets, the effects of MBDSW on the cAMP level in collagen-activated platelets were investigated. As shown in Fig. 5A, MBDSW $(\mathrm{H} 2,000)$ increased the cAMP level. In addition, dipyridamole $(40 \mu \mathrm{M})$, a PDE inhibitor, significantly increased the cAMP level and VASP $\left(\operatorname{ser}^{157}\right)$ phosphorylation. (Figs. 5A and S3).

MBDSW decreases $T X A_{2}$ production. Upon exposure to collagen, the platelet membrane is catabolized from a phospholipid to TXA ${ }_{2}$. The produced $\mathrm{TXA}_{2}$ acts as a positive feedback mediator in the activation of nearby platelets (26). Therefore, in this study, whether MBDSW decreases the production of $\mathrm{TXA}_{2}$ under collagen exposure was then examined. In this experiment, $\mathrm{TXA}_{2}$ was detected using $\mathrm{TXB}_{2}$, a stable metabolite of $\mathrm{TXA}_{2}$. The results revealed that treatment with collagen $(3 \mu \mathrm{g} / \mathrm{ml})$ markedly increased $\mathrm{TXB}_{2}$ production; however, the platelets pre-treated with MBDSW exhibited significantly decreased $\mathrm{TXB}_{2}$ levels, with the reduction occurring in a hardness-dependent manner (Fig. 5B).

MBDSW inhibits Akt and ERK phosphorylation. Previous studies have demonstrated that Akt plays a role in the amplification of platelet aggregation, granule secretion and integrin $\alpha_{\mathrm{IIb}} \beta_{3}$ activation induced by agonists $(16,17)$; therefore, this study investigated whether MBDSW inhibits the collagen-stimulated phosphorylation of Akt; the results revealed that the inhibition of Akt phosphorylation occurred in a hardness-dependent manner (Fig. 6A).

MAPKs, including ERK, JNK and p38, are activated and phosphorylated in platelets following treatment with various agonists (18). Thus, this study whether MBDSW downregulates MAPKs. The results revealed that MBDSW inhibits the phosphorylation of ERK, in a hardness-dependent manner; however, it did not inhibit the phosphorylation of JNK or p38 (Fig. 6B).

LY294002 and U0126 inhibit Akt and ERK phosphorylation. In addition, it was investigated whether LY294002, an Akt inhibitor, or U0126, an ERK inhibitor, can cross-inhibit the phosphorylation of Akt and ERK. Collagen $(3 \mu \mathrm{g} / \mathrm{ml})$ was shown to extensively increase phosphorylation of Akt and ERK. By contrast, both LY294002 and U0126 markedly inhibited the phosphorylation of Akt and ERK (Fig. 7A and B). In addition, dipyridamole inhibited the phosphorylation of Akt and ERK (Fig. S3). 

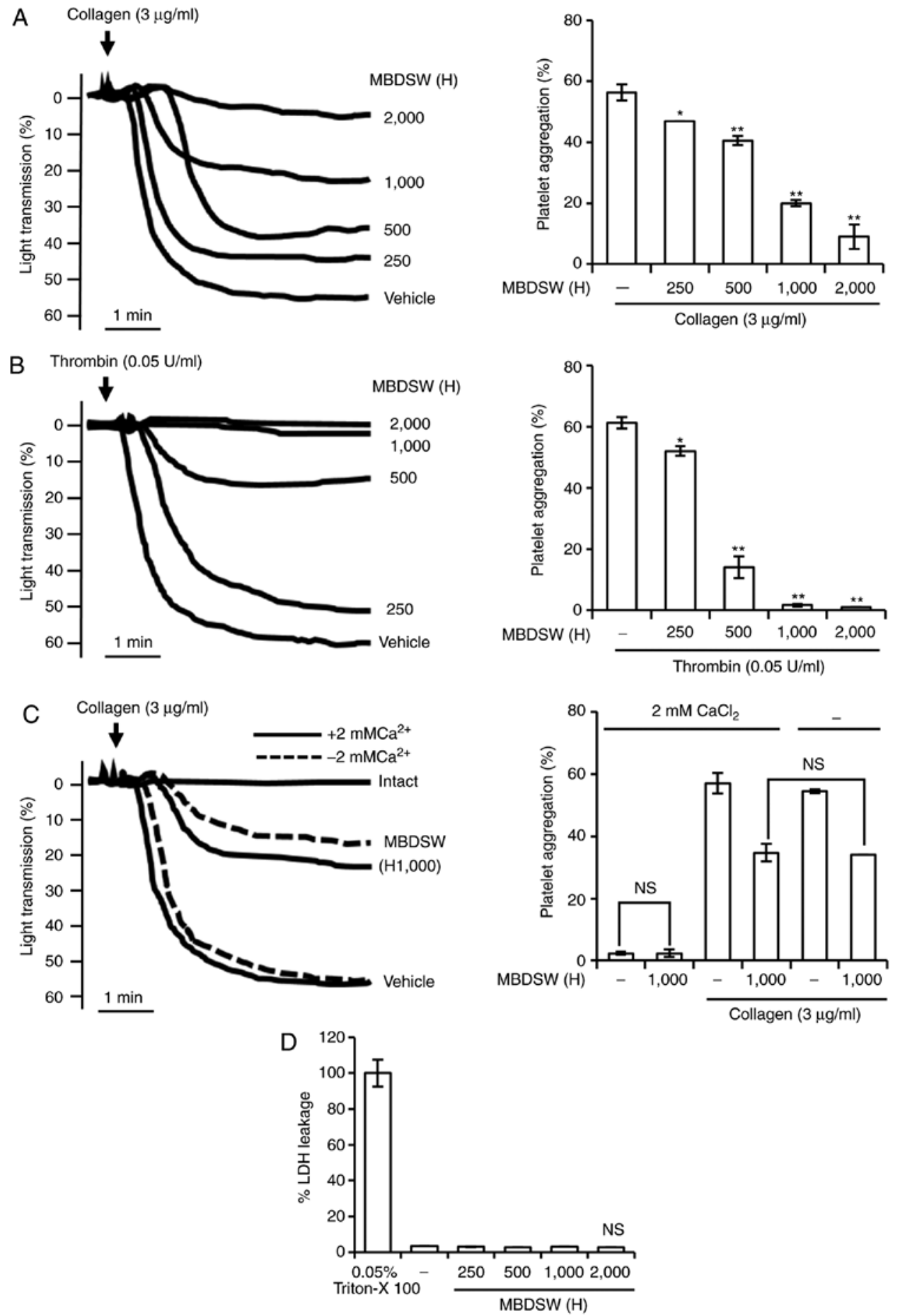

Figure 1. Inhibitory activity of MBDSW on agonist-induced human platelet aggregation, and cytotoxicity. (A) Washed human platelets $\left(1 \times 10^{8}\right.$ cells $\left./ \mathrm{ml}\right)$ were pre-incubated with MBDSW at various levels of hardness (H250, 500, 1,000 and 2,000) and subsequently treated with collagen (3 $\mu \mathrm{g} / \mathrm{ml})$ to induce platelet aggregation. (B) Washed human platelets $\left(1 \times 10^{8} \mathrm{cells} / \mathrm{ml}\right)$ were pre-incubated with MBDSW at various levels of hardness (H250,500, 1,000 and 2,000) and subsequently treated with thrombin $(0.05 \mathrm{U} / \mathrm{ml})$ to induce platelet aggregation. (C) Washed human platelets $\left(1 \times 10^{8}\right.$ cells $\left./ \mathrm{ml}\right)$ were pre-incubated with MBDSW $(\mathrm{H} 1,000)$ or the vehicle in the presence or absence of $2 \mathrm{mM} \mathrm{CaCl}_{2}$ and subsequently treated with collagen $(3 \mu \mathrm{g} / \mathrm{ml})$. (D) Effects of MBDSW on cytotoxicity. MBDSW $(\mathrm{H})$ was at the ratio of $\mathrm{Mg}: \mathrm{Ca}, 3: 1$, and hardness. All data are presented as the means $\pm \mathrm{SD}(\mathrm{n}=3)$. Vehicle is collagen only. NS, not significant. ${ }^{*} \mathrm{P}<0.05$ and ${ }^{* *} \mathrm{P}<0.001$ vs. the vehicle. $\mathrm{H}$, hardness; MBDSW, mineral-balanced deep sea water.

\section{Discussion}

CVDs are the most common underlying cause of mortality in developed nations and are associated with various risk factors, such as abnormal cholesterol levels, high blood pressure, diabetes, smoking and obesity $(27,28)$. In addition, the activation of platelets, which is caused by a series of processes, can increase the risk of CVDs, when combined with risk factors (29). Previous studies have demonstrated that MBDSW can regulate various risk factors for CVDs $(7,9,11,30-32)$; however, there is incomplete information on its effects on platelet activation. Therefore, the present study evaluated the 

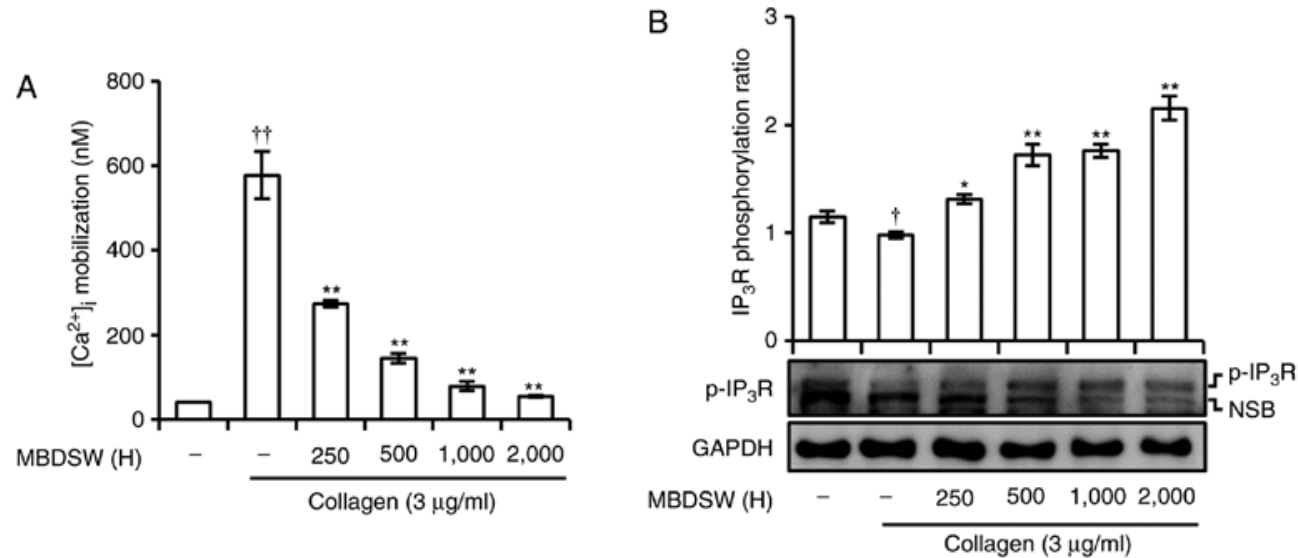

Figure 2. Inhibitory effects of MBDSW on collagen-induced cytosolic calcium ion concentration and IP3R phosphorylation. (A) Washed platelets were loaded with Fura-2/AM at $37^{\circ} \mathrm{C}$ for $1 \mathrm{~h}$. Fura-2/AM-loaded platelets were pretreated with MBDSW at $37^{\circ} \mathrm{C}$ for 2 min and stimulated with collagen $(3 \mu \mathrm{g} / \mathrm{ml})$ Fluorescence was recorded with a spectrofluorometer (SFM 25). (B) Washed platelets were pre-incubated with MBDSW at $37^{\circ} \mathrm{C}$ for $2 \mathrm{~min}$ and stimulated with collagen $(3 \mu \mathrm{g} / \mathrm{ml})$. Platelet aggregation was terminated by the addition of protease and phosphatase inhibitor-contained RIPA lysis buffer; the phosphorylation of IP3R was examined by western blot analysis. All data are presented as the means $\pm \mathrm{SD}(\mathrm{n}=3)$. NSB, non-specific band. ${ }^{\dagger} \mathrm{P}<0.05$ and ${ }^{\dagger} \mathrm{P}<0.001 \mathrm{vs}$. intact; ${ }^{*} \mathrm{P}<0.05$ and ${ }^{* *} \mathrm{P}<0.001$ vs. collagen-activated control. H, hardness; MBDSW, mineral-balanced deep sea water; IP3R, inositol 1,4,5-triphosphate receptor.
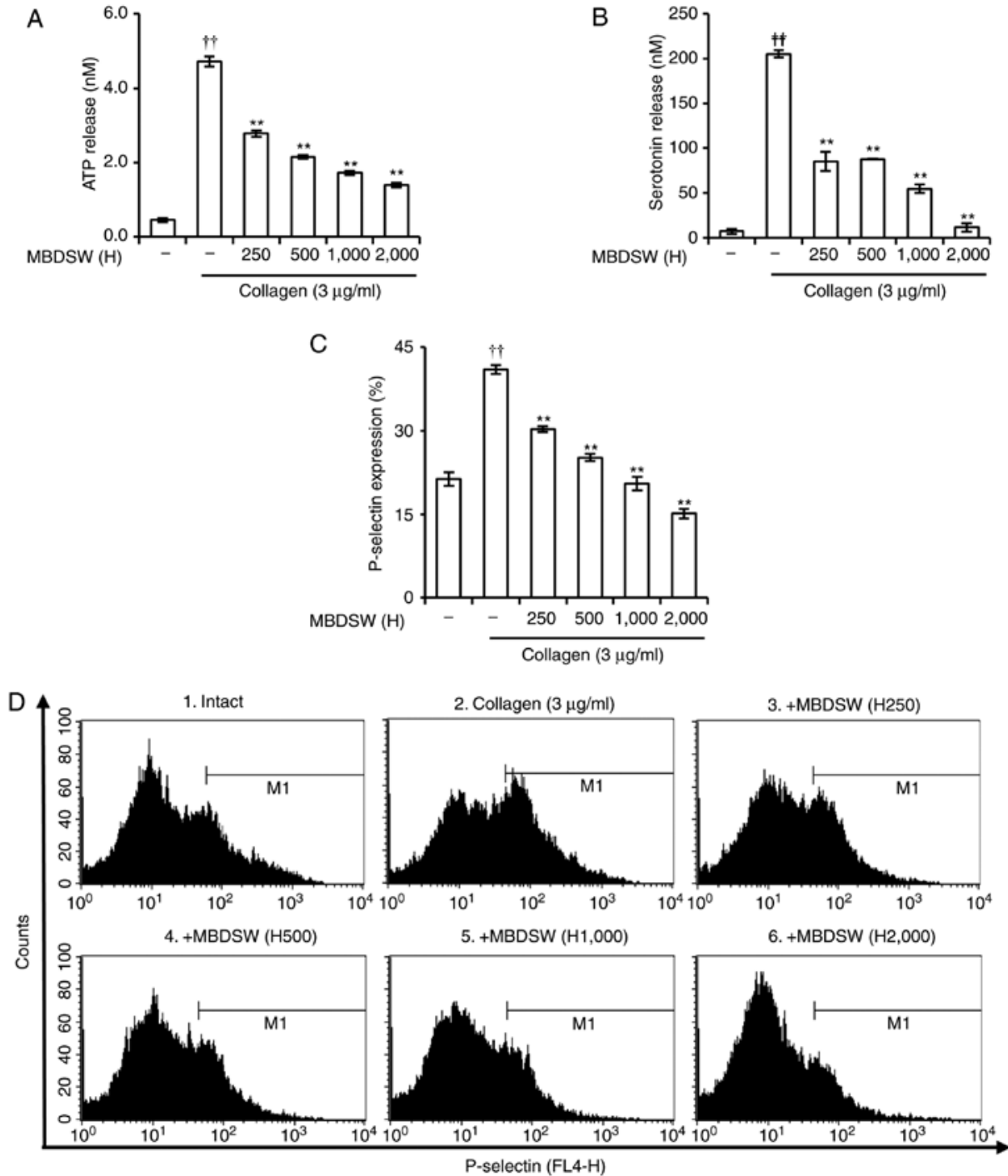

Figure 3. Effects of MBDSW on collagen-induced $\alpha$-granule and dense granule secretions. (A) Effect of MBDSW on ATP release. (B) Effect of MBDSW on serotonin release. (C) Flow cytometric histograms of collagen-induced P-selectin expression. (D) Effect of MBDSW on P-selectin expression. Washed platelets were incubated with MBDSW at $37^{\circ} \mathrm{C}$ for $2 \mathrm{~min}$, and the platelets were then stimulated with collagen $(3 \mu \mathrm{g} / \mathrm{ml})$ for 5 min. ATP and serotonin release was determined using an ELISA assay kit. P-selectin expression was assessed using a FACSCalibur II flow cytometer. All data are presented as the means \pm SD $(\mathrm{n}=3) .{ }^{\dagger} \mathrm{P}<0.001$ vs. intact; ${ }^{* *} \mathrm{P}<0.001$ vs. collagen-activated control. $\mathrm{H}$, hardness; MBDSW, mineral-balanced deep sea water. 

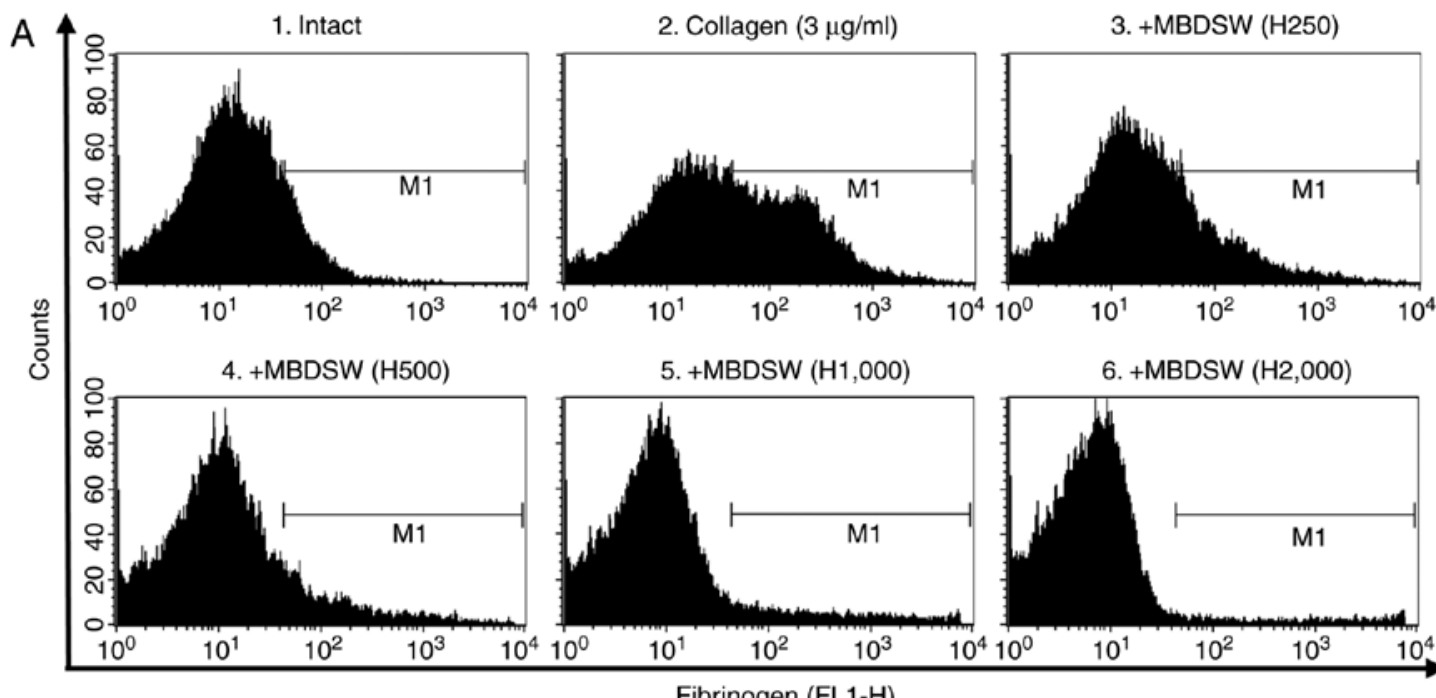

5. + MBDSW $(\mathrm{H} 1,000)$

6. + MBDSW $(\mathrm{H} 2,000)$

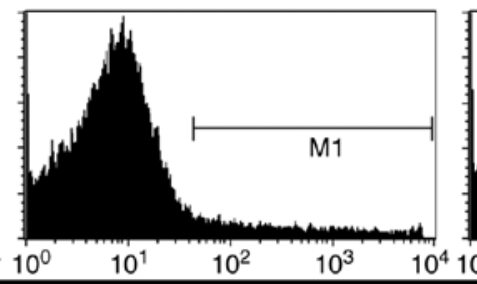

Fibrinogen (FL1-H)

B

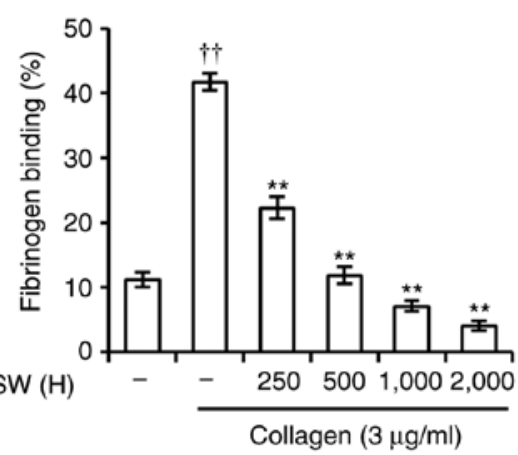
$\operatorname{MBDSW}(\mathrm{H})$
C

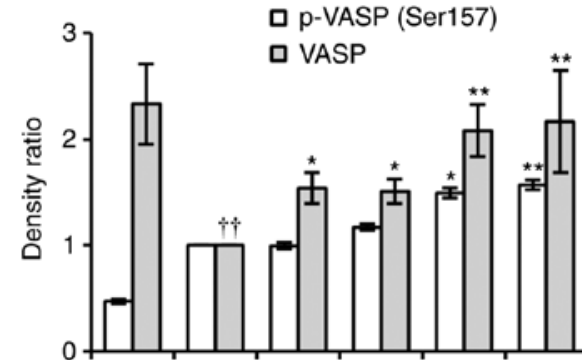

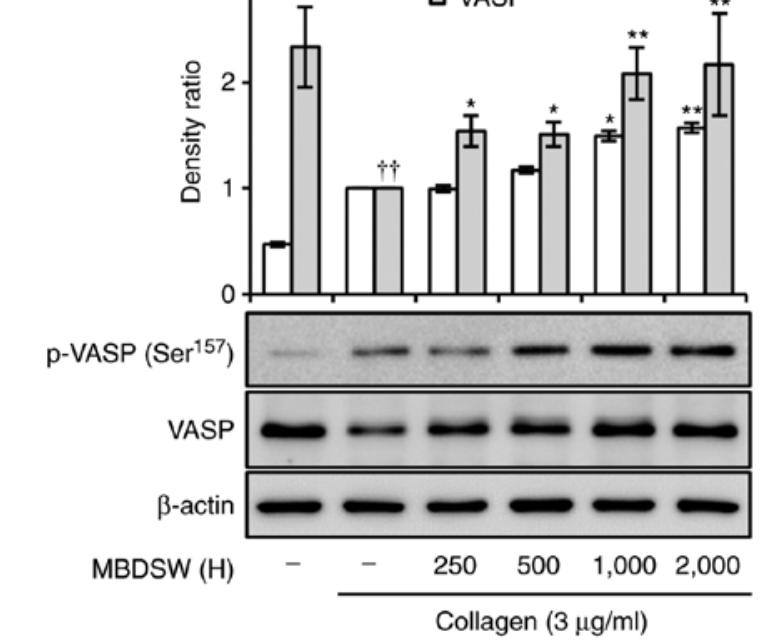

\begin{abstract}
Figure 4. Effects of MBDSW on fibrinogen binding to integrin $\alpha_{\mathrm{II}} \beta_{3}$ and on phosphorylated VASP (Ser $\left.{ }^{157}\right)$ in collagen-stimulated platelets. (A) Flow cytometric histograms of collagen-induced fibrinogen binding to integrin $\alpha_{\mathrm{II}} \beta_{3}$. (B) Effect of MBDSW on collagen-induced fibrinogen binding to integrin $\alpha_{\mathrm{II}} \beta_{3}$. (C) Effect of MBDSW on VASP ( $\mathrm{Ser}^{157}$ ) phosphorylation and density ratio in collagen-activated platelets. All data are presented as the means \pm SD $(\mathrm{n}=3$ ). ${ }^{\dagger} \mathrm{P}<0.001$ vs. intact; ${ }^{*} \mathrm{P}<0.05$ and ${ }^{* * *} \mathrm{P}<0.001$ vs. collagen-activated control. $\mathrm{H}$, hardness; MBDSW, mineral-balanced deep sea water; VASP, vasodilator-stimulated phosphoprotein.
\end{abstract}

inhibitory effects of MBDSW on platelet activity by analyzing granule release, integrin $\alpha_{\mathrm{IIb}} \beta_{3}$ activation, calcium mobilization, $\mathrm{TXA}_{2}$ production, $\mathrm{cAMP}$ level, and the functioning of the Akt and MAPK pathways.

When the extracellular matrix of the blood vessel wall is damaged, the released collagen induces platelet aggregation; thrombin, a coagulation protein produced during the coagulation process, also causes platelet aggregation $(4,33)$. Although these mechanisms differ, they ultimately produce the same result; platelet aggregation and activation. Therefore, this study initially examined whether MBDSW can inhibit both collagen- and thrombin-induced platelet aggregation. As shown in Fig. 1A and B, MBDSW markedly inhibited collagen- and thrombin-induced platelet aggregation in a hardness-dependent manner. In addition, the presence of calcium in MBDSW did not automatically affect platelet aggregation (Fig. 1C). This indicates that calcium, which is essential for platelet activation, is abundant in MBDSW but does not affect for platelet aggregation. In addition, MBDSW contains $\mathrm{Mg}, \mathrm{K}, \mathrm{Na}$ and $\mathrm{Sr}$. $\mathrm{Mg}$ and $\mathrm{K}$ are known to inhibit platelet aggregation and $\mathrm{Na}$ intake tends to increase platelet aggregation $(34,35)$. However, the suspension buffer contains much higher $\mathrm{Na}$ and $\mathrm{K}$ concentrations than MBDSW. Therefore, $\mathrm{Na}$ and $\mathrm{K}$ in MBDSW are not affected [suspension buffer, $138 \mathrm{mM}$ $\mathrm{NaCl}, 2.7 \mathrm{mM} \mathrm{KCl}$ and MBDSW (H2,000): $1 \mathrm{mM} \mathrm{Na}$, $0.25 \mathrm{mM} \mathrm{K}]$. Sr is an antagonist of calcium and is known to act similar to calcium in the platelet aggregation (36). However, MBDSW contains a very small amount of strontium and will not be affected. In this study Fig. S2 shows $\mathrm{Ca}$ and $\mathrm{Mg}$ information for platelet aggregation. However, more detailed research is required and thus further studies need to be carried out on this matter.

To elucidate the underlying inhibitory mechanisms of MBDSW, platelet activation markers and downstream molecules were investigated. To determine whether MBDSW 
A
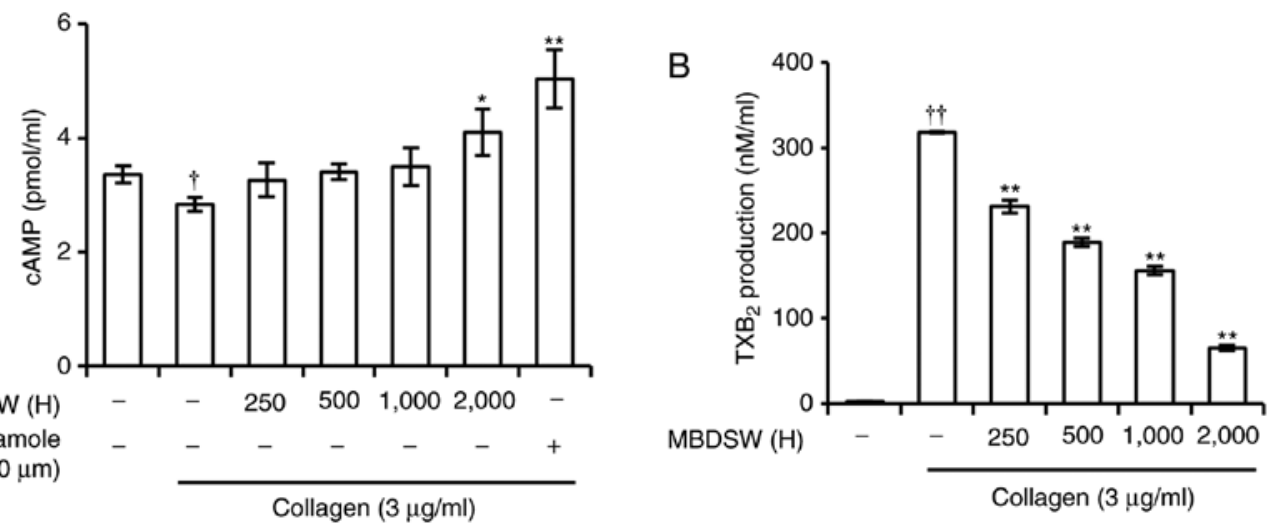

Figure 5. Effects of MBDSW on the cAMP level and TXA2 production. (A) After terminating the collagen-induced platelet aggregation, the cAMP level was assayed using a cAMP ELISA kit according to the manufacturer's protocol. (B) After terminating the collagen-induced platelet aggregation, $\mathrm{TXA}_{2}$ was determined with the content of $\mathrm{TXB}_{2}$ using a $\mathrm{TXB}_{2}$ ELISA kit according to the manufacturer's protocol. All data are presented as the means $\pm \mathrm{SD}$ ( $\mathrm{n}=3$ ). ${ }^{\dagger} \mathrm{P}<0.05$ and ${ }^{~} \mathrm{P}<0.001$ vs. intact; ${ }^{\mathrm{P}}<0.05$ and ${ }^{* * *} \mathrm{P}<0.001$ vs. collagen-activated control. $\mathrm{H}$, hardness; MBDSW, mineral-balanced deep sea water; cAMP, cyclic adenosine monophosphate; TXA2, thromboxane $\mathrm{A}_{2} ; \mathrm{TXB}_{2}$, thromboxane $\mathrm{B}_{2}$.
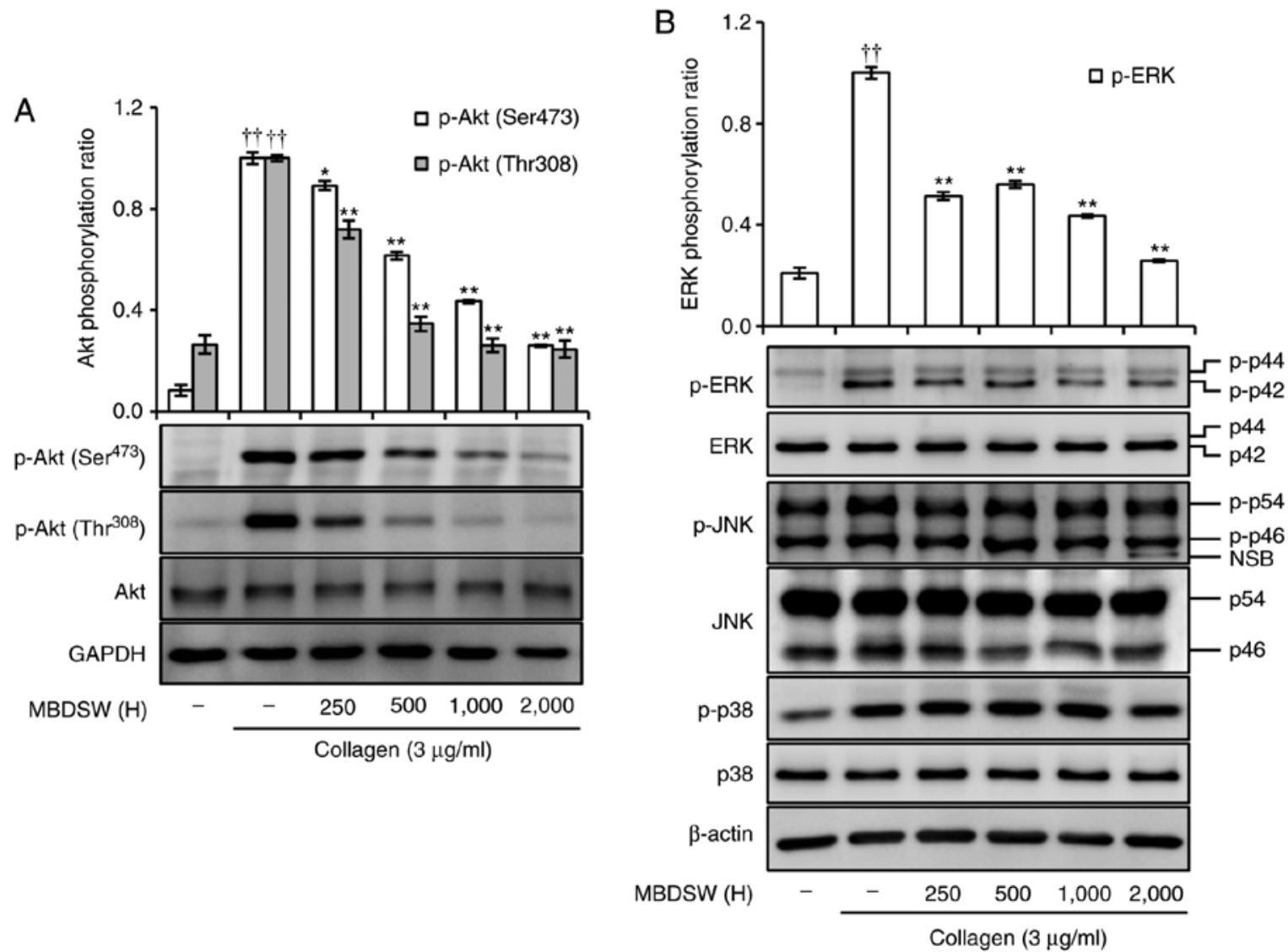

Figure 6. Effects of MBDSW on Akt and MAPK phosphorylation. (A) Effects of MBDSW on Akt phosphorylation and density ratio in collagen-activated platelets. (B) Effects of MBDSW on MAPK phosphorylation and ERK phosphorylation density ratio in collagen-activated platelets. The levels were measured by western blot analysis as described in the 'Materials and methods' section. All data are presented as the means \pm SD ( $n=3)$. ERK was detected as p44/p42 and JNK was detected as p54/p46. NSB, non-specific band. ${ }^{\dagger} \mathrm{P}<0.001$ vs. intact; $\mathrm{P}<0.05$ and ${ }^{* * *} \mathrm{P}<0.001$ vs. collagen-activated control. H, hardness; MBDSW, mineral-balanced deep sea water; ERK, extracellular signal-regulated kinase; JNK, c-Jun N-terminal kinase.

regulates the intracellular calcium levels, a calcium assay was carried out using a fluorescence spectrophotometer. The data revealed that MBDSW significantly decreased the collagen-induced intracellular calcium levels in a hardness-dependent manner (Fig. 2A). The $\mathrm{IP}_{3}$ generated by phospholipase $\mathrm{C}$ is able to release $\left[\mathrm{Ca}^{2+}\right]_{\mathrm{i}}$ from the endoplasmic reticulum by directly activating $\mathrm{IP}_{3} \mathrm{R}$ channels. In platelets, the regulation of this receptor is considered to occur through receptor phosphorylation. Previous studies have reported the inhibition of $\mathrm{IP}_{3} \mathrm{R}$ function following phosphorylation $(37,38)$. This study demonstrated that MBDSW markedly increased the phosphorylation of $\mathrm{IP}_{3} \mathrm{R}$ (Fig. 2B). In platelets, 


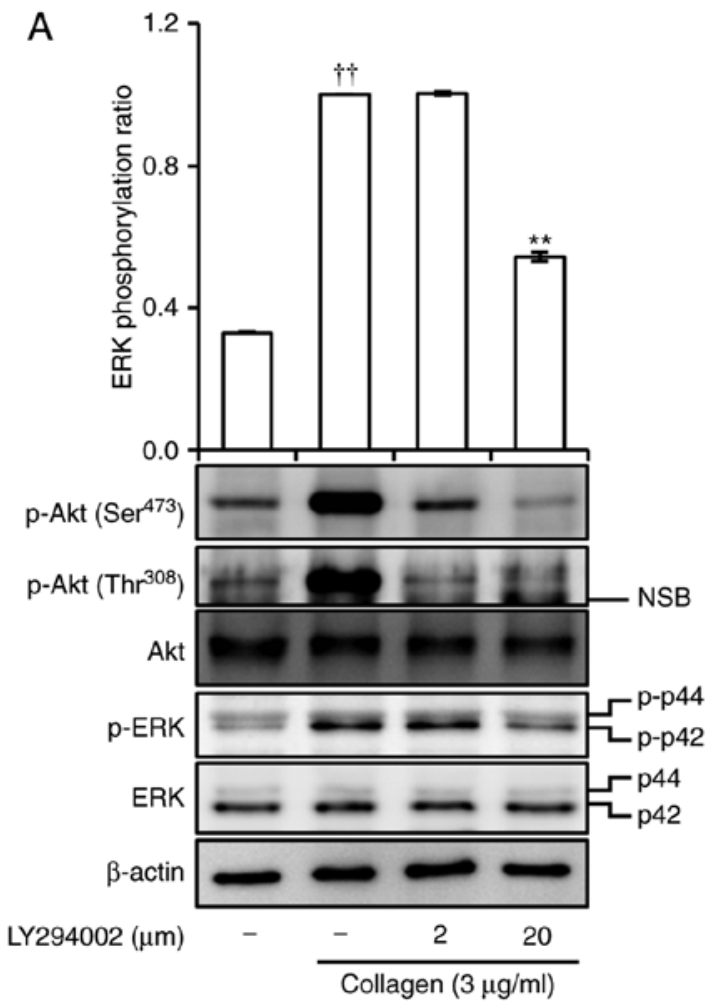

B

口 p-Akt (Ser473) a p-Akt (Thr308)

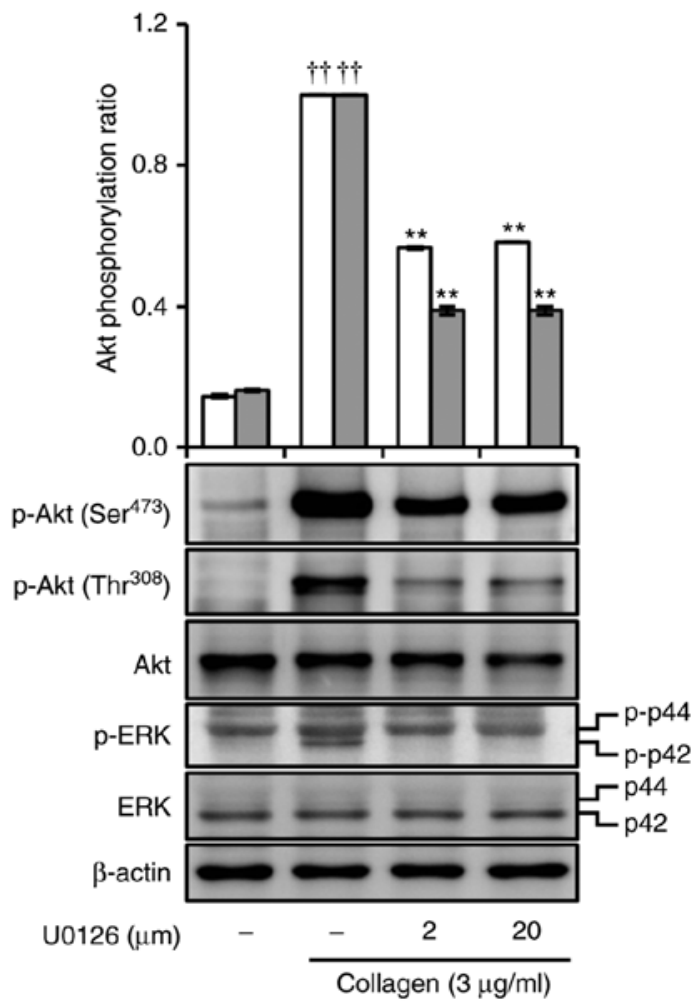

Figure 7. Effects of LY294002 and U0126 on Akt and MAPK phosphorylation. (A) Effects of LY294002 on Akt and ERK phosphorylation, and ERK phosphorylation density ratio in collagen-activated platelets. (B) Effects of U0126 on Akt and ERK phosphorylation and Akt phosphorylation density ratio in collagen-activated platelets. The levels were measured by western blot analysis as described in the 'Materials and methods' section. All data are presented as the means \pm SD $(n=3)$. ERK was detected as p44/p42. NSB, non-specific band. ${ }^{\dagger} \mathrm{P}<0.001$ vs. intact; ${ }^{* *} \mathrm{P}<0.001 \mathrm{vs}$. collagen-activated control. $\mathrm{H}$, hardness; MBDSW, mineral-balanced deep sea water; ERK, extracellular signal-regulated kinase.

functions including degranulation, adhesion and thrombus formation are activated by an elevation in the intracellular calcium level (22). Hence, these results suggest that MBDSW containing calcium inhibits collagen-induced calcium mobilization via the phosphorylation of $\mathrm{IP}_{3} \mathrm{R}$. Moreover, it is also suggested that MBDSW can prevent calcium-dependent signaling in platelets. A previous study suggested that the calcium/calmodulin-induced phosphorylation of the myosin light chain contributes to platelet granule secretion (39).

Platelet $\alpha$-granules contain protein molecules, such as coagulation factors (e.g., fibrinogen, factor V), growth factors (e.g., platelet-derived growth factor, epidermal growth factor) and adhesion molecules (P-selectin). Dense granules contain small non-protein molecules, such as adenosine diphosphate, ATP and serotonin that amplify the activation of platelets (40). We found that MBDSW significantly inhibited P-selectin expression and dense granule secretion (Fig. 3). These results indicate that MBDSW, by suppressing P-selectin expression, inhibits platelet-mediated inflammation and leukocyte migration during thrombus formation and prevents platelet aggregation .

In platelets, abundant integrin $\alpha_{\text {IIb }} \beta_{3}$ plays an essential role in both inside-out and outside-in signaling. Integrin $\alpha_{\text {IIb }} \beta_{3}$-mediated signaling transduction is achieved when it binds to fibrinogen, which leads to platelet aggregation (41). In this study, MBDSW markedly inhibited its binding to fibrinogen, blocking inside-out signaling (Fig. 4A and B).
VASP links the extracellular matrix through integrin to the actin cytoskeleton and is involved in the inactivation of integrin, and Akt is required for full activation of integrin and granule secretion $(16,17)$. In the present study, it was demonstrated that MBDSW activated VASP $\left(\mathrm{Ser}^{157}\right)$ and inactivated the phosphorylation of Akt (Figs. 4C and 6A). This result indicates that MBDSW inhibits the activation of integrin $\alpha_{\text {IIb }} \beta_{3}$ by regulating both VASP and Akt. In addition, the activation of integrin $\alpha_{\mathrm{II}} \beta_{3}$ and granule secretion are known to be inhibited by the cAMP pathway $(42,43)$. As the cAMP pathway inhibits the activation of integrin $\alpha_{\mathrm{II}} \beta_{3}$ and granule secretion through VASP and Akt proteins, this study examined whether MBDSW increases the cAMP level. MBDSW $(\mathrm{H} 250-\mathrm{H} 1,000)$ restored the cAMP level to that of unstimulated platelets, although this change was not significant. However, MBDSW did increase the cAMP level at H2,000 (Fig. 5A).

Further investigation of the molecular mechanisms revealed that MBDSW may target ERK (Fig. 6B). Indeed, human platelets contain the MAPK family and Akt proteins, and these proteins are involved in the platelet activation, adhesion, and granule secretion (16-18). However, this study demonstrated that p38 and JNK are not the targets of MBDSW, based on the observation that MBDSW failed to inhibit the phosphorylation of $\mathrm{p} 38$ and JNK (Fig. 6B). Since MBDSW selectively suppressed the phosphorylation of Akt and ERK, whether the cross-inhibition of Akt and ERK was possible was investigated. The phosphorylation of Akt and ERK was assessed by using LY294002, an 
Akt inhibitor, and U0126, an ERK inhibitor, to confirm the association between Akt and ERK pathway signaling. As shown in Fig. 7, LY294002 inhibited the phosphorylation of ERK and U0126 inhibited the phosphorylation of Akt. Furthermore, it was determined whether dipyridamole can regulate the phosphorylation of Akt, ERK and VASP $\left(\operatorname{Ser}^{157}\right)$. The results revealed that dipyridamole increased the cAMP levels and regulated the phosphorylation of Akt, ERK and VASP ( $\mathrm{Ser}^{157}$ ) (Figs. 5A and S3). These results suggest that MBDSW can cross-inhibit ERK and Akt via an increase in the cAMP level. Moreover, the activation of ERK increases TXA $\mathrm{T}_{2}$ production through cytosolic phospholipase $A_{2}$ (44). MBDSW significantly inhibited the production of $\mathrm{TXA}_{2}$ (Fig. 5B), suggesting that MBDSW more effectively inhibits the production of $\mathrm{TXA}_{2}$ through the inhibition of ERK phosphorylation. The released $\mathrm{TXA}_{2}$, serotonin, and ATP act as positive feedback mediators in the activation of more platelets to participated in platelet aggregation $(31,45,46)$. Therefore, the inhibition of secretion of these molecules by MBDSW is a source of effective inhibition of platelet aggregation.

Platelet aggregation influences the development of CVDs. Of note, the majority of risk factors of CVDs, including hypercholesterolemia, hypertension, smoking and diabetes are able to increase platelet activation (47-50). In other study, DSW has been shown to be effective in reducing CVD risk factors $(7,9,11,13,14)$. The present study demonstrated that platelet aggregation was markedly inhibited by MBDSW that contains abundant $\mathrm{Mg}$. Therefore, the results suggest that $\mathrm{Mg}$ in MBDSW is a key component in determining the anti-platelet aggregation activity of MBDSW.

In conclusion, this study demonstrated that the inhibitory effect of MBDSW on collagen- and thrombin-induced platelet aggregation occurred in a hardness-dependent manner. In addition, MBDSW markedly suppressed intracellular downstream signal transduction; that is, MBDSW significantly inhibited collagen-induced $\left[\mathrm{Ca}^{2+}\right]_{i}$ mobilization, granule secretion and $\mathrm{TXA}_{2}$ production. Furthermore, it was found that MBDSW regulated the cAMP level and the phosphorylation of ERK, Akt and VASP $\left(\operatorname{Ser}^{157}\right)$. Finally, the activity of integrin $\alpha_{\mathrm{IIb}} \beta_{3}$ was inhibited by MBDSW. Anti-platelet drugs used for the prevention and treatment of thrombosis target $\mathrm{TXA}_{2}$ production, integrin inhibition and increases in cAMP levels (51); therefore, MBDSW can be regarded as a potential prophylactic agent for application in the prevention of CVDs.

\section{Acknowledgements}

Not applicable.

\section{Funding}

This study was financially supported by the National R\&D project 'Development of new application technology for deep seawater industry' supported by the Ministry of Oceans and Fisheries of the Republic of Korea.

\section{Availability of data and materials}

All data generated or analyzed during this study are included in this published article or are available from the corresponding author on reasonable request.

\section{Authors' contributions}

KSN and GSN designed the experiments. KSN, GSN and KSL analyzed and interpreted the data. GSN performed the experiments and wrote the manuscript. All authors have read and approved the final manuscript.

\section{Ethics approval and consent to participate}

This study was approved by Dongguk University Gyeongju Institutional Review Board (DUG IRB 20180014-04).

\section{Patient consent for publication}

Not applicable.

\section{Competing interests}

The authors declare that they have no competing interests.

\section{References}

1. Kuter DJ: The physiology of platelet production. Stem Cells 14 (Suppl 1): S88-S101, 1996.

2. Huo Y and Ley KF: Role of platelets in the development of atherosclerosis. Trends Cardiovasc Med 14: 18-22, 2004.

3. Farndale RW, Sixma JJ, Barnes MJ and de Groot PG: The role of collagen in thrombosis and hemostasis. J Thromb Haemost 2: 561-573, 2004.

4. Barnes MJ and Farndale RW: Collagens and atherosclerosis. Exp Gerontol 34: 513-525, 1999.

5. Jin J, Quinton TM, Zhang J, Rittenhouse SE and Kunapuli SP: Adenosine diphosphate (ADP)-induced thromboxane A(2) generation in human platelets requires coordinated signaling through integrin alpha(IIb)beta(3) and ADP receptors. Blood 99: 193-198, 2002.

6. Flaumenhaft R: Molecular basis of platelet granule secretion. Arterioscler Thromb Vasc Biol 23: 1152-1160, 2003.

7. Hwang HS, Kim HA, Lee SH and Yun JW: Anti-obesity and antidiabetic effects of deep sea water on ob/ob mice. Mar Biotechnol (NY) 11: 531-539, 2016.

8. Hataguchi Y, Tai H,Nakajima Hand KimataH:Drinking deep-sea water restores mineral imbalance in atopic eczema/dermatitis syndrome. Eur J Clin Nutr 59: 1093-1096, 2005.

9. Lee KS, Kwon YS, Kim S, Moon DS, Kim HJ and Nam KS: Regulatory mechanism of mineral-balanced deep sea water on hypocholesterolemic effects in HepG2 hepatic cells. Biomed Pharmacother 86: 405-413, 2017.

10. Lee KS, Chun SY, Lee MG, Kim S, Jang TJ and Nam KS: The prevention of TNF- $\alpha /$ IFN- $\gamma$ mixture-induced inflammation in human keratinocyte and atopic dermatitis-like skin lesions in $\mathrm{Nc} / \mathrm{Nga}$ mice by mineral-balanced deep sea water. Biomed Pharmacother 97: 1331-1340, 2018.

11. Sheu MJ, Chou PY, Lin WH, Pan CH, Chien YC, Chung YL, Liu FC and Wu CH: Deep sea water modulates blood pressure and exhibits hypolipidemic effects via the AMPK-ACC pathway: An in vivo study. Mar Drugs 11: 2183-2202, 2013.

12. Lee KS, Shin JS, Kwon YS, Moon DS and Nam KS: Suppression of cancer progression and metastasis in HT-29 human colorectal adenocarcinomas by deep sea water. Biotechnol Bioprocess Eng 18: 194-200, 2013.

13. Miyamura M, Yoshioka S, Hamada A, Takuma D, Yokota J, Kusunose M, Kyotani S, Kawakita H, Odani K, Tsutsui Y and Nishioka Y: Difference between deep seawater and surface seawater in the preventive effect of atherosclerosis. Biol Pharm Bull 27: 1784-1787, 2004.

14. Lee KS, Chun SY, Kwon YS, Kim S and Nam KS: Deep sea water improves hypercholesterolemia and hepatic lipid accumulation through the regulation of hepatic lipid metabolic gene expression. Mol Med Rep 15: 2814-2822, 2017.

15. Chun SY, Kim S and Nam KS: The inhibitory effects of deep-sea water on doxorubicin-induced epithelial-mesenchymal transition. Oncol Rep 38: 1163-1171, 2017. 
16. Chen J, De S, Damron DS, Chen WS, Hay N and Byzova TV: Impaired platelet responses to thrombin and collagen in AKT-1-deficient mice. Blood 104: 1703-1710, 2004.

17. Stojanovic A, Marjanovic JA, Brovkovych VM, Peng X, Hay N, Skidgel RA and Du X: A phosphoinositide 3-kinase-AKT-nitric oxide-cGMP signaling pathway in stimulating platelet secretion and aggregation. J Biol Chem 281: 16333-16339, 2006.

18. Flevaris P, Li Z, Zhang G, Zheng Y, Liu J and Du X: Two distinct roles of mitogen-activated protein kinases in platelets and a novel Rac1-MAPK-dependent integrin outside-in retractile signaling pathway. Blood 113: 893-901, 2009.

19. Heemskerk JW, Bevers EM and Lindhout T: Platelet activation and blood coagulation. Thromb Haemost 88: 186-193, 2002.

20. Rittenhouse-Simmons S and Deykin D: Isolation of membranes from normal and thrombin treated gel-filtered platelets using a lectin marker. Biochim Biophys Acta 426: 688-696, 1976.

21. Schaeffer J and Blaustein MP: Platelet free calcium concentrations measured with fura- 2 are influenced by the transmembrane sodium gradient. Cell Calcium 10: 101-113, 1989.

22. Nesbitt WS, Giuliano S, Kulkarni S, Dopheide SM, Harper IS and Jackson SP: Intercellular calcium communication regulates platelet aggregation and thrombus growth. J Cell Biol 160: 1151-1161, 2003.

23. Shattil SJ and Newman PJ: Integrins: Dynamic scaffolds for adhesion and signaling in platelets. Blood 104: 1606-1615, 2004.

24. Reinhard M, Jarchau T and Walter U: Actin-based motility: Stop and go with Ena/VASP proteins. Trends Biochem Sci 26 : 243-249, 2001

25. Gambaryan S, Kobsar A, Rukoyatkina N, Herterich S, Geiger J, Smolenski A, Lohmann SM and Walter U: Thrombin and collagen induce a feedback inhibitory signaling pathway in platelets involving dissociation of the catalytic subunit of protein kinase A from an NFkappaB-IkappaB complex. J Biol Chem 285: 18352-18363, 2010

26. Paul BZ, Jin J and Kunapuli SP: Molecular mechanism of thromboxane A(2)-induced platelet aggregation. Essential role for p2t(ac) and alpha(2a) receptors. J Biol Chem 274: 29108-29114, 1999.

27. Mathur RK: Role of diabetes, hypertension, and cigarette smoking on atherosclerosis. J Cardiovasc Dis Res 1: 64-68, 2010

28. O'Donnell CJ and Elosua R: Cardiovascular risk factors. Insights from Framingham Heart Study. Rev Esp Cardiol 61: 299-310, 2008 (In Spanish).

29. Willoughby S, Holmes A and Loscalzo J: Platelets and cardiovascular disease. Eur J Cardiovasc Nurs 1: 273-288, 2002.

30. Ha BG, Shin EJ, Park JE and Shon YH: Anti-diabetic effect of balanced deep-sea water and its mode of action in high-fat diet induced diabetic mice. Mar Drugs 11: 4193-4212, 2013.

31. Katsuda S, Yasukawa T, Nakagawa K, Miyake M, Yamasaki M, Katahira K, Mohri M, Shimizu T and Hazama A: Deep-sea water improves cardiovascular hemodynamics in kurosawa and kusanagi-hypercholesterolemic (KHC) rabbits. Biol Pharm Bull 31: 38-44, 2008.

32. Yoshioka S, Hamada A, Cui T, Yokota J, Yamamoto S, Kusunose M, Miyamura M, Kyotani S, Kaneda R, Tsutsui Y, et al: Pharmacological activity of deep-sea water: Examination of hyperlipemia prevention and medical treatment effect. Biol Pharm Bull 26: 1552-1559, 2003.

33. Borissoff JI, Spronk HM, Heeneman S and ten Cate H: Is thrombin a key player in the 'coagulation-atherogenesis' maze? Cardiovasc Res 82: 392-403, 2009.
34. Gawaz M, Ott I, Reininger AJ and Neumann FJ: Effects of magnesium on platelet aggregation and adhesion. Magnesium modulates surface expression of glycoproteins on platelets in vitro and ex vivo. Thromb Haemost 72: 912-918, 1994.

35. Gow IF, Padfield PL, Reid M, Stewart SE, Edwards CR and Williams BC: High sodium intake increases platelet aggregation in normal females. J Hypertens (Suppl 5): S243-S246, 1987.

36. Togna G, Gallozzi S and Caprino L: Influence of strontium chloride on blood platelet function. Arch Toxicol 63: 366-369, 1989.

37. Komalavilas $P$ and Lincoln TM: Phosphorylation of the inositol 1,4,5-trisphosphate receptor by cyclic GMP-dependent protein kinase. J Biol Chem 269: 8701-8707, 1994.

38. Supattapone S, Danoff SK, Theibert A, Joseph SK, Steiner J and Snyder SH: Cyclic AMP-dependent phosphorylation of a brain inositol trisphosphate receptor decreases its release of calcium. Proc Natl Acad Sci USA 85: 8747-8750, 1988.

39. Nishikawa M, Tanaka T and Hidaka H: Ca2+-calmodulindependent phosphorylation and platelet secretion. Nature 287: 863-865, 1980

40. Reed GL, Fitzgerald ML and Polgár J: Molecular mechanisms of platelet exocytosis: Insights into the 'secrete' life of thrombocytes. Blood 96: 3334-3342, 2000.

41. Payrastre B, Missy K, Trumel C, Bodin S, Plantavid M and Chap H: The integrin alpha IIb/ beta 3 in human platelet signal transduction. Biochem Pharmacol 60: 1069-1074, 2000.

42. Smolenski A: Novel roles of cAMP/cGMP-dependent signaling in platelets. J Thromb Haemost 10: 167-176, 2012.

43. Kim S, Jee K, Kim D, Koh H and Chung J: Cyclic AMP inhibits Akt activity by blocking the membrane localization of PDK1. J Biol Chem 276: 12864-12870, 2001.

44. Lin LL, Wartmann M, Lin AY, Knopf JL, Seth A and Davis RJ: cPLA2 is phosphorylated and activated by MAP kinase. Cell 72: 269-278, 1993

45. Birk AV, Broekman MJ, Gladek EM, Robertson HD, Drosopoulos JH, Marcus AJ and Szeto HH: Role of extracellular ATP metabolism in regulation of platelet reactivity. J Lab Clin Med 140: 166-175, 2002.

46. Cerrito F, Lazzaro MP, Gaudio E, Arminio P and Aloisi G: 5HT2-receptors and serotonin release: Their role in human platelet aggregation. Life Sci 53: 209-215, 1993.

47. Bröijersén A,Hamsten A,Eriksson M, Angelin B and Hjemdahl P Platelet activity in vivo in hyperlipoproteinemia-importance of combined hyperlipidemia. Thromb Haemost 79: 268-275, 1998.

48. Nityanand S, Pande I, Bajpai VK, Singh L, Chandra M and Singh BN: Platelets in essential hypertension. Thromb Res 72: 447-454, 1993.

49. Nowak J, Murray JJ, Oates JA and FitzGerald GA: Biochemical evidence of a chronic abnormality in platelet and vascular function in healthy individuals who smoke cigarettes. Circulation 76 : 6-14, 1987.

50. Manduteanu I, Calb M, Lupu C, Simionescu N and Simionescu M Increased adhesion of human diabetic platelets to cultured valvular endothelial cells. J Submicrosc Cytol Pathol 24: 539-547, 1992

51. Eikelboom JW, Hirsh J, Spencer FA, Baglin TP and Weitz JI Antiplatelet drugs: Antithrombotic therapy and prevention of thrombosis, 9th ed: American college of chest physicians evidence-based clinical practice Guidelines. Chest 141 (2 Suppl): e89S-e119S, 2012. 